Acta Hispanica (2020) Supplementum II: 587-598

\title{
POESÍA CUBANA TRADUCIDA POR JOSEPH BRODSKY
}

\section{DARIA SINITCYNA}

\author{
Universidad Estatal de San Petersburgo
}

\begin{abstract}
Resumen: El caso de Joseph Brodsky (1940-1996), premio Nobel de literatura, es un ejemplo del destino de un poeta en el universo soviético. Compartió con otros autores censurados la imposibilidad de expresarse con libertad a través de la poesía e, igual que B. Pasternak, O. Mandelshtam, M. Tsvetaeva y muchos más, recurrió a lo largo de los 60 a la traducción poética como recurso de sobrevivir pero también como una válvula de escape para la creación literaria. Tradujo autores ingleses, norteamericanos, polacos, yugoslavos, españoles, argentinos y en dos casos, cubanos. Se conocen las versiones rusas de poemas de Pablo Armando Fernández, Virgilio Piñera, Eugenio Florit y Ángel Augier realizadas por Brodsky. El análisis de estas traducciones supone el estudio del balance entre la coyuntura del momento histórico, la elección de los textos a traducir, la presencia del texto mediador (podstrochnik) y la relevancia del texto resultante para la cultura recipiente y revela varios aspectos importantes tanto de la obra de Joseph Brodsky como de las realidades de la escritura y la traducción en la época socialista.
\end{abstract}

Palabras clave: contacto soviético-cubano, traducción literaria, escuela soviética de traducción.

\begin{abstract}
The case of Joseph Brodsky (1940-1996), Nobel Prize for literature, is an example of the destiny of a poet in the Soviet universe. He shared with other censored authors the inability to express themselves freely through poetry and, like B. Pasternak, O. Mandelshtam, M. Tsvetaeva and many more, used poetic translation throughout the 60 s as a resource to survive but also as an escape valve for literary creation. He translated English, American, Polish, Yugoslavian, Spanish, Argentinian and, in two cases, Cuban authors. The Russian versions of poems by Pablo Armando Fernández, Virgilio Piñera, Eugenio Florit and Ángel Augier by Brodsky are known. The analysis of these translations involves the study of the balance between the requirements of the historical moment, the choice of the texts to be translated, the presence of the mediating text (podstrocbnik) and the relevance of the resulting text for the recipient culture and reveals several important aspects of both the work of Joseph Brodsky as of the realities of writing and translation in the socialist era.
\end{abstract}

Keywords: Soviet-Cuban Contact, Literary Translation, Soviet School of Translation.

Uno de los rasgos distintivos de la cultura rusa del siglo XX es que está fuertemente marcada por la literatura (y en primer lugar, poesía) extranjera traducida al ruso. Las razones de esta percepción sensible y profunda son múltiples: por un lado, es el mensaje global propagado por el nuevo Estado soviético que reclamaba lo mejor de la cultura mundial para sus ciudadanos y, entre otras iniciativas, fundó para este fin la editorial "Literatura universal" (V semirnaya literatura) cuyos colaboradores se preocuparon por crear criterios y métodos de producir traducciones literarias de alta calidad. Por otro lado, es el resultado de la hermeticidad de la sociedad soviética donde, al estar cerrado el acceso al grueso de la 
cultura occidental, lo poco que entraba gozaba de una elevada atención por parte del lector. Tampoco es de olvidarse la tercera razón: muchos escritores, sobre todo poetas, después de que se les había negado el derecho a la publicación por no encajar en las pautas del arte soviético, se dedicaron a la traducción literaria guiados por motivos económicos y por la esperanza de encontrar en este tipo de creación una especie de válvula de escape para su talento. Vsevolod Bagno señala al respecto:

[...] la censura, la presión ideológica contra los artistas, unos ataques sin precedentes que se acometían en la prensa contra la palabra libre obligaron a los grandes poetas a partir de los finales de los años 20 a recurrir, con más frecuencia de lo que les gustaría, a la traducción como fuente de ingresos cuando su propia obra quedaba prohibida. Con lo cual, el recurso de los autores extranjeros se convertía en un "nicho" en el que se refugiaron muchos de los destacados poetas rusos [...] El "nicho" pocas veces servía para el consuelo de un poeta y aún menos veces se concretaba en una morada cómoda. Pero dentro de él (tanto en los años 30-40, como en los 60-70) pasaban mucho más tiempo de lo que quisieran incluso los poetas que se habían descubierto a sí mismos en la traducción y cuyo don poético florecía en sus traducciones con la misma fuerza y profundidad que en su obra original (Багно, 2016: 30) ${ }^{1}$.

Son, por ejemplo, los casos, de Boris Pasternak, Anna Ajmatova, Marina Tsvetaeva, Osip Mandelshtam, Nikolay Zabolotskiy, Arseniy Tarkovskiy, Mikhail Kuzmin etc. Es también el caso de Joseph (Iosif) Brodsky (1940-1996), poeta, ensayista y dramaturgo, quinto premio Nobel de la literatura rusa (1987).

La problemática de un poeta como traductor literario en la sociedad soviética es compleja y nunca puede reducirse a las cuestiones prácticas de supervivencia, mucho menos cuando se trata de Brodsky, ya que entre sus méritos siempre se reconoce la introducción de la riqueza versificadora e imaginativa de la poesía inglesa y norteamericana en el campo poético del idioma ruso. A lo largo de su trayectoria, en circunstancias diversas Brodsky estuvo traduciendo a autores ingleses, estadounidenses, españoles, serbios, checos, polacos, lituanos, australianos, cubanos, griegos, italianos, holandeses, estonios, georgianos, etc. Es conocido por sus traducciones de John Donne, Constantino Cavafis, Czeslaw Milosz, Konstanty Ildefons Galczynski, Salvatore Quasimodo y otros. Las traducciones están incluidas en sus obras escogidas y en dos ocasiones, se publicaron como libros aparte. La crítica ha destacado la relevancia de esta faceta de la obra de Brodsky en varios aspectos. Viktor Kulle habla del reto global: "Lo que hace única la experiencia de Brodsky es que se sentía abierto, cosa algo inusual para nuestra cultura, a TODA la experiencia de la poesía mundial entendida como un organismo vivo y entero [...] Las traducciones [...] entran, a veces muchos años después,

${ }^{1}$ La traducción del ruso al español de todas las citas es mía - D. S. 
en diálogo con sus poemas originales” (Кул^э, 1992: 5-6) у del enriquecimiento profesional: "[...] la virtuosidad de la versificación, la variedad increíble de herramientas es el "efecto lateral" de la actividad de Brodsky como traductor" (Кум^э, 1996: 8). Yakov Gordin, citando al propio poeta, califica la traducción como "una tarea casi antropológica” y la describe como misión:

Su trabajo de traductor era una parte orgánica de una lucha tenaz contra la barbarie en todas sus manifestaciones, desde el despotismo político hasta una cultura de masas agresiva y vulgar. [...] Una deuda con la cultura. Las traducciones, incluidas las del español, eran una forma de transición, un sistema de vasos comunicantes, una manera de cobrar y pagar esta deuda (Гордин, 2016: 68).

Por supuesto, en la obra de Brodsky las traducciones constituyen una jerarquía interna, y se supone que la poesía cubana ocupa uno de los peldaños más bajos. Se le conocen las traducciones de dos poemas de Eugenio Florit, dos de Ángel Augier, uno de Pablo Armando Fernández y uno de Virgilio Piñera y ninguno figura en las obras escogidas ni en la colección de traducciones, ambas ediciones publicadas en vida y aprobada la selección por el autor. Por lo visto, no los consideraba relevantes. Es un hecho conocido que Brodsky, quien había abandonado la secundaria a los quince años, estudió solo el inglés y el polaco para poder leer la obra original de autores que escribían en estos idiomas. En cambio, no se propuso aprender el español aunque le interesaba la estructura métrica y estrófica de la poesía española, que estudiaba, sin embargo, en textos traducidos. Kulle menciona que tan temprano como entre 1957 y 1960 "vive unos cambios vertiginosos de influencias en la versificación, entre ellas, la poesía traducida de Lorca, Ritsos, Hikmet” (Кум^э, 1996: 8).

Entre 1956 y 1964, Brodsky, además de escribir poesía y comunicarse con otros poetas, ejerce trabajos más diversos que no tienen ninguna relación con la creación literaria. Sin ver oportunidades de publicar su obra, a principio de los 60 entra en el "nicho" (en términos de V. Bagno) y de esta manera se convierte en "poeta-traductor". Es relevante el análisis de este devenir realizado por Y. Klots:

Brodsky's name, no doubt, belongs to the list of Russian poettranslators, who, while trying to make their way into print and earn a living, fertilized Russian poetry with hitherto unknown masterpieces of world literature, even though accomplishing this mission would require them also to translate heaps of "ideologically friendly" production which did not necessarily agree with their own poetics but often exceeded in number their translations chosen for aesthetic reasons and non-conformist purposes [...] (Klots, 2011: 188-189). 
La primera publicación de Brodsky es precisamente el resultado de su trabajo como poeta-traductor: la traducción del poema "B" ("Mi boca no dirá...") de Pablo Armando Fernández en la antología "Aurora sobre Cuba" (Zarya nad Kuboy), que salió en 1962 e incluía poemas de autores cubanos y latinoamericanos, mayormente con el tema de la revolución de 1959.

Dejando de momento a un lado la cuestión de la calidad estética de esta traducción en concreto, fijémonos en la descripción de la colección y la característica del autor del poema original:

The history of the few official publications of Joseph Brodsky in Soviet Russia begins in the fall of 1962, when his translation of a poem by Pablo Armando Fernandez, a "progressive" Cuban poet, appeared in the anthology Заря над Kyбой [Dawn Above Cuba], commissioned, essentially, as part of the Soviet campaign to promote comradely writers from abroad in the USSR" (Klots, 2011: 188).

El adjetivo "progresivo" usado por el discurso oficial pasaba a adquirir un significado negativo para los autores como Brodsky, opuestos al régimen: si a un poeta lo recomendaban como "progresivo" era probable que pertenecía a esas toneladas de producción "ideológicamente amistosa" (otro término oficial) y su valor literario podía ser nulo, ya que el compromiso con la ideología comunista bastaba para ser apreciado y publicado en la URSS. Andrey Sergeev, poeta, traductor y amigo de Brodsky, recuerda el día cuando lo conoció (3 de enero de 1964) usando el mismo vocablo: "Iosif me visitó con un propósito: Anna Ajmatova le había pasado mi número de teléfono. Iosif tenía ganas de traducir algo limpio. En aquel entonces se consideraban limpias las traducciones de un idioma occidental y de un autor no progresivo" (Сергеев, 2013: 37).

El afán de traducir "algo limpio” que Brodsky, según Sergeev, manifestaba en las primeras fechas de 1964 es, en cierto sentido, la prueba de que nunca había visto sus traducciones como una mera manera de ganar dinero o de negociar con las autoridades. El 29 de noviembre de 1963, se había publicado en el diario Vecherniy Leningrad un artículo titulado "Un zángano paraliterario" que contenía calumnias contra Brodsky y lo acusaba de "parasitismo social", es decir, de no tener trabajo fijo, lo que significa que, al conocer a Sergeev, Brodsky, de hecho, estaba ya bajo la amenaza de una detención y un proceso judicial, que no tardaron en ocurrir. Si en aquellas circunstancias prefería un texto no comprometido, mucho menos hubiera escogido algo que no coincidiera con su propia poética cuando no corría riesgo. Es curioso que, para poner un ejemplo a la afirmación de V. Kulle -"Establecer una barrera entre las traducciones de Brodsky hechas "por razones de corazón" y las que le permitían ganarse la vida es una tarea bastante arriesgada” (Кум^э, 1992: 282-283)-, Y. Gordin recurre a la poesía cubana: 
En efecto, leyendo hoy las traducciones de Brodsky de, pongamos por caso, la poesía cubana, uno se lleva la sorpresa de no encontrar ningún trazo de un mínimo compromiso con la ideología. De lo que ofrecía la "isla de la libertad" castrista, Brodsky elegía poemas absolutamente dignas y que en muchos casos entraban en su sistema de ver el mundo (ГорАин, 2016: 61).

La traducción del poema de Fernández, junto con las de dos poetas yugoslavos, la de unas coplas del argentino José Ramón Luna y varias de Konstanty Ildefons Galczynski (estas últimas sin publicar, pero famosas en los círculos literarios de Leningrado y Moscú, ya que Brodsky los había recitado en unas reuniones) en marzo de 1964 sirvieron de argumento de defensa en el juicio que acusaba a Brodsky del delito administrativo de "parasitismo social". Como sabemos de los apuntes que hizo la periodista Frida Vigdorova en la sala y que se publicaron por primera vez en los años de la perestroika con el título "Una farsa judicial", tanto la abogada como los tres testigos de defensa mencionaron la labor de Brodsky como poeta-traductor. A la vez, tuvieron que explicar al tribunal el proceso de la traducción literaria en el diálogo entre la abogada y Natalia Grudinina, poeta y traductora, asesora de jóvenes autores leningradenses en varias organizaciones profesionales:
Abogada: ¿Es necesario conocer la obra entera de un autor para traducir sus poemas?
Grudinina: Sí, para hacer una buena traducción, semejante a las de Brodsky, hay que conocer la obra de un autor e impregnarse de su voz.
Abogada: ¿Si una traducción fue hecha usando una traducción interlineal (podstrochnik) $)^{2}$ se reduce el pago?
Grudinina: Sí, se reduce. Cuando yo traducía a poetas húngaros, cobraba un rublo menos por cada línea (en moneda antigua).
Abogada: ¿Muchos traductores practican la traducción mediante interlineal?
Grudinina: Sí, es una práctica común. Uno de los traductores leningradenses más destacados, A. Gitovich, siempre usa interlineales en sus traducciones de la poesía china antigua. [...]
Abogada: Si Brodsky no domina el idioma serbio ¿es capaz, a pesar de ello, de realizar una traducción literaria de alta calidad?
Grudinina: Sí, por supuesto.
Abogada: ¿Usted no considera la interlineal un abuso de labor ajena? Grudinina: Dios me guarde (Вигдорова, 1988: 28).

\footnotetext{
${ }^{2}$ Una traducción literal no versificada realizada por un filólogo y usada por un poeta-traductor como una especie de producto prefabricado. La absoluta mayoría de las traducciones poéticas en la URSS se realizaban mediante una interlineal.
} 
Efim Etkind y Wolf Admoni, ambos filólogos y traductores profesionales, trataron en sus intervenciones como testigos de defensa de hacer que los acusadores entendieran la enorme labor que supone una traducción siquiera de un poema y elogiar el mérito de Brodsky. Sin embargo, la estrategia de la defensa no funcionó y Brodsky fue sentenciado a cinco años de trabajos forzados y un exilio en un pueblo del norte de Rusia, de donde regresó un año y cinco meses después. El plazo había sido reducido por la presión de la comunidad internacional pero también por los juegos internos de los servicios de seguridad, según muestra Olga Edelman (ЭАельман, 2007). A partir de entonces y hasta su exilio en 1972, Brodsky fue condenado a ser un poeta "mudo". En octubre de 1965 fue aceptado como miembro de la sección de traductores de la sucursal leningradense de la Unión de Escritores de la URSS, hecho que lo protegió de posibles acusaciones nuevas de "parasitismo".

En 1968, con una tirada de 10000 ejemplares se publicó la antología titulada "Isla de aurora purpúrea" (Ostrov zari bagryanoy) (Фейхоо, 1968). Compuesta por Samuel Feijoo, contenía textos de 39 autores cubanos empezando por José Martí y terminando por Miguel Barnet. La estructura de la colección deja la sensación de un "truco" bastante común en el mundo de editoriales y revistas soviéticas que manejaban las letras extranjeras. El formato de una antología de la literatura de una nación "ideológicamente amistosa" permitía un intento de traducir y publicar a autores no comprometidos con el régimen de su país de procedencia, como Julián del Casal, Mariano Brull, Dulce María Loynaz, Eugenio Florit, Virgilio Piñera o José Lezama Lima, si eran aliñados con una buena dosis de los comprometidos, como Nicolás Guillén y Juan Marinello, y puestos bajo una tapa con una línea de la canción soviética más famosa sobre la Revolución cubana (Kuba - lyubov moyal "Cuba mi amor").

De los 28 traductores que colaboraron en "Isla de aurora purpúrea", diez son hispanistas profesionales (Anatoliy Geleskul, Ovadiy Savich, Pavel Grushko, Valeriy Stolbov, entre otros), tres son traductores literarios de otros idiomas, a uno (G. Chizh) no logramos identificar, y catorce son "poetas-traductores". En la lista de estos últimos figuran tanto autores de un destino profesional muy favorable, "acariciados" por el régimen, como Ilya Ehrenburg, Rimma Kazakova o Evgeny Evtushenko, como los escritores que compartían con Joseph Brodsky la "mudez" poética, fuese por motivos políticos (Evgeny Ternovsky, Nina Voronel, Konstantin Azadovsky) o no (Alexandr Golemba, Eduard Golderness). A Brodsky en la antología de 1968 le pertenecen, además del antes publicado "Mi boca no dirá..." de Fernández, las traducciones de "Cuatro canciones" y "Seguro pensamiento" de Eugenio Florit, "Vesperal" y "Lunes" de Ángel Augier y "Vida de Flora" de Virgilio Piñera. Entre estos seis textos, "Vida de Flora" se presenta como el más cercano a la poética del propio Brodsky del período post-exilio norteño, cuando de poemas abstractos y románticos pasa a una estética de imágenes tangibles, tono coloquial y entonación "neutra". En el marco del presente artículo vamos a centrar el análisis en la traducción de este poema únicamente. 
Las pautas formales de la traducción poética que guiaban a los traductores de la URSS habían sido formulados por Nikolay Gumilev en el folleto "Principios de la traducción literaria" (Гумилев, Чуковский, 1919) publicado por la editorial "Literatura universal". Al final de su artículo "Sobre las traducciones versificadas" los proclamaba de la manera más breve posible y los llamaba "los nueve mandamientos". La lista incluía los elementos de la poética del texto original que un traductor debía obedecer y conservar y comenzaba por el "número de líneas". Por supuesto, una traducción que observara todos los mandamientos de Gumilev era un caso más bien raro, ya que el seguir las reglas no garantizaba una producción poética a la altura del original y, lo que es más importante, que correspondiera a los requisitos de un supuesto lector ideal en la cultura recipiente. La actitud de Brodsky hacia las normas de traducción era, por lo visto, complicada. En el número de la revista Literaturnoe obozrenie (Núm. 3, 1996) dedicado a la memoria del poeta, se publicaron por primera vez algunas de sus traducciones, entre otros, el poema de Reed Whittemore "A Day with the Foreign Legion". Comentándola, V. Kulle señala:

Es una traducción única en la obra de Brodsky. Tiene treinta líneas más que el original [...] Un poeta que afirma que la discrepancia de los pies métricos en la traducción es la discrepancia del aliento y de las contracciones del músculo cardíaco aquí se permite una libertad inexplicable [...] Como si el traductor "completase" al autor molesto porque este no hubiera podido desplegar el tema que se había propuesto (КулАэ, 1996: 9).

Con la ocasión de otra traducción de Brodsky, de Vítězslav Nezval, Oleg Malevich, traductor y especialista en filología checa, entrevistado para un programa de radio evocaba lo siguiente:

$\mathrm{Al}$ recibir las traducciones hechas, todos vieron que Brodsky había traducido aquellos poemas según su estilo creativo, absolutamente opuesto al de Nezval. En Nezval, cada estrofa es una frase completa sin ningún tipo de violación de límites y la traducción de Brodsky se componía de puros enjambements. Y no sabíamos qué hacer. Invité a Brodsky, le expliqué que era una falta de compaginación en sus poéticas individuales y le pregunté si podía hacer algo para corregirlo. Y me dijo que no, no podía hacer nada (Вашкова, 2007).

Si los dos casos mencionados de un tratamiento libre del texto original por parte de Brodsky registran los hechos, la carta que dirigió a la editora responsable de la publicación de las obras de Galczynski y que cita Rada Alloy en su biografía "Un alegre acompañante" revela los motivos de sus estrategias: 
Poesía cubana traducida por Joseph Brodsky

En los pocos casos en que me alejé del original [...] no lo hice por no poder componer algo equivalente sino porque partía de mi visión del lector a quien deberíamos echarle la mano en un mundo nuevo para él [...] Para un polaco, el maestro de magia negra, el paisaje de Cracovia, el latín y los chistes sobre el más allá son cosas que conoce desde niño. Y para nuestro lector son un poco oscuras. Por tanto, me parece peligroso ser demasiado literal en esta traducción. Que sea un poquito más larga y pintoresca, pero más comprensible (А^^ой, 2008: 56).

En la misma carta parece responder a los reproches de desobedecer la regla de número igual de líneas y se niega a cambiar su traducción: "Creo que es más largo con dos líneas. Bueno, que no me paguen por ellas y ya... Me siento y no me siento culpable. Saludos, I. Brodsky" (А^^ой, 2008: 56). Es curioso que Brodsky como traductor en este caso aspira a que el texto sea más comprensible para el lector (hay que tener en cuenta que se trata de la primera mitad de los 60), una actitud difícil de esperar de un autor más bien hermético, admirador de los poetas "metafísicos” del Renacimiento inglés.

Habiendo observado varias tácticas de Brodsky como traductor, presentemos el análisis de su versión de "Vida de Flora" como un texto bilingüe donde los elementos ausentes en el original o alterados de alguna manera en la traducción vienen en cursiva:

Vida de Flora
Жизнь ФАоры

Tú tenías grandes pies y un tacón jorobado.

У тебя были большие ноги. И горбатый каблук. И больщие ноги.

Ponte la flor. Espérame, que vamos juntos de viaje.

Приколи цветок. ПодожАи меня. Прогуляемся вместе.

Tú tenías grandes pies. ¡Qué tristeza en el aire!

У тебя были большие ноги. И печальный вид. Но казалосв:

¿Quién se mordía la cola? ¿Quién cantaba ese aire?

ноги больще печали. Печаль была незаметна. Я не видел печали.

Небъгтие незаметно твои ноги всосало.

Это уже одно говорит о его размерах.

Tú tenías grandes pies, mi amiga en seco parada.

Ноги твои больше как вкопанные остановились.

Una gran luz te brotaba. De los pies, digo, te brotaba,

Ты изцучала свет. Ноги, говорю, излучали.

y sin que nadie lo supiera te fue sorbiendo la nada.

Un gran ruido se sentía en tu cuarto. ¿A Flora qué le pasa? 
Nada, que sus grandes pies ocupan todo el espacio.

Sí, tú tenías, tenías la imponderable amargura de un zapato.

Горечь стоптанных туфель... была в тебе эта горечь.

Ibas y venías entre dos calientes planchas:

ВзаА и впереА ты сновала, как маятник, меж утюгами.

Flora, mucho cuidado, que tus pies son muy grandes,

Осторожней, ФАора! У тебя очень большие ноги!

y la peletería te contrata para exhibir sus hormas gigantes.

И обувная фирма наняла тебя Аля рекламы.

Flora, cuántas veces recorrías el barrio

Сколько улиц ты обошла, Фцора, в поисках масла, pidiendo un poco de aceite y el brillo de la luna te encantaba.

сколько раз свет цуны тебя очаровывац, Флора?

De pronto subían tus dos monstruos a la cama,

И вАруг на постель взлетали два твоих великана, tus monstruos horrorizados por una cucaracha.

испуганные появлением маленького таракана.

Flora, tus medias rojas cuelgan como lenguas de ahorcados.

Качаются тихо, Фцора, как языки повешенных, Флора, красные чулки твои, Флора.

¿En qué pies poner estas huérfanas? ¿Adónde tus últimos zapatos? Чьи теперь ноги, Флора, приютят этих сирот, Флора, кому отАать твои туфми?

Oye, Flora: tus pies no caben en el río que te ha de conducir a la nada,

Послушай, ФАора, твои колоссальные ноги не поместятся в Axероне.

al país en que no hay grandes pies ni pequeñas manos ni ahorcados. Какже пльть тебе, Флора, в ту страну, гАе размеры ног не играют роли?

Tú querías que tocaran el tambor para que las aves bajaran, Ты просима, чтоб бил барабан, чтоб птицы спустились с naлbмbl.

las aves cantando entre tus dedos mientras el tambor repicaba.

Что ж, я усльшиал дробъ, а птицы запели, оседлав твои пальцы.

Un aire feroz ondulando por la rigidez de tus plantas, Жесткий ветер шуршит у твоих неподвижных подошв. Я занят todo eso que tú pensabas cuando la plancha te doblegaba.

звонким пением птич. Но не слыму этого хора. 
Poesía cubana traducida por Joseph Brodsky

Flora, te voy a acompañar hasta tu última morada.

Приколи иветок. Я тебя провожу... Аай я возьму на память

Tú tenías grandes pies y un tacón jorobado.

об огромныхх твоих ногах горбатый каблук твой, Флора (Фейхоо, 1968: 173-174).

Los cambios formales introducidos por Brodsky no son muy numerosos pero saltan a la vista. Algunos de ellos se presentan como un desarrollo de un recurso utilizado por Piñera: si el poeta-autor divide una línea en dos oraciones ("Ponte la flor. Espérame, que vamos juntos de viaje."), el poeta-traductor, la divide en tres y en más ocasiones a lo largo del poema. La traducción literal inversa de la primera línea sería: "Tú tenías grandes pies. Y un tacón jorobado. Y unos grandes pies.”. Otro ejemplo de la proliferación de un elemento poético del original es la multiplicación del vocativo "Flora": en la estrofa de "las medias rojas" sale cinco veces en ruso contra una en español. Una llamada repetitiva la comunica a la traducción el tono de un conjuro que entra en juego con el "encantamiento" de la luna y, junto con el fraccionamiento de la línea en tres sintagmas, parece contribuir a la imitación de un ritmo de blues. Otros cambios de forma, que no dependen de lo ofrecido por la poética de Piñera, se deben probablemente al dictado del idioma. En su discurso Nobel, Brodsky expresa la idea de que un poeta es la herramienta del idioma y no al revés (Бродский, 1992). En "Vida de Flora" vemos que no solo convierte la rima asonante de Piñera en una más variable: en tres ocasiones, subrayadas en el esquema bilingüe, la convierte en una rima femenina más estricta introduciendo los vocablos de consonantes similares, como si fuera una tentación irresistible. El "efecto dominó" provocado por este cambio estilístico produce unas nuevas imágenes: en la

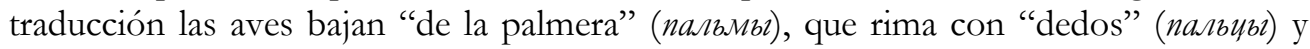
quizás sea una innovación menos apropiada de todas hechas por Brodsky, ya que deja escapar una "tropicalidad" no justificada en el espacio "neutro" típico para los textos de Piñera. Es más significativa la transformación del "río que te ha de conducir a la nada" en "el Aqueronte", ya que su aparición en el texto no es solo cuestión de rima sino la señal de la gran importancia de la cultura griega y romana antigua para el universo poético de Brodsky. Es muy poco probable que conociera a Piñera como autor de "Electra Garrigó" pero de alguna manera, a lo mejor, apoyándose en el nombre de la protagonista, Brodsky percibe una onda afín a su poética en el texto cubano y la pone a vibrar.

En cuanto a las alteraciones del contenido del poema, el más significativo es la presencia mucho más firme y amplia del "yo", el interlocutor de Flora en la traducción. Este "yo" se apodera por completo de la segunda estrofa, véase la comparación del original con la traducción literal inversa: 
Tú tenías grandes pies. ¡Qué tristeza en el aire!

Tú tenías grandes pies. Y un aire de tristeza. Pero parecía

¿Quién se mordía la cola? ¿Quién cantaba ese aire?

que los pies eran más grandes que la tristeza. La tristeza no se notaba. Yo no vi la tristeza.

En vez de una ausencia del sujeto que deja preguntas sin respuesta (“¿Quién...?”) sale el interlocutor que se reafirma, ya que no simplemente registra el aspecto de Flora sino proclama su percepción ("Yo no vi..."). Es un cambio de perspectiva que encontramos también en la metamorfosis de "el tambor repicaba", que se convierte en "Bueno, yo oí el repique" (Что ж, я усльишал дробъ...). Cuanto más se acerca el final del poema, el "уо" tiende más a imponer su visión. En vez de conservar la imagen de la plancha que "doblega" a la protagonista, sigue concentrado en los pájaros de la estrofa anterior: "Estoy ocupado con el canto sonoro de los pájaros. Pero no oigo este coro". Como era de esperar, la lógica expansiva del "yo" le confiere la voz en la coda del poema. Es sumamente extraño que Brodsky sacrifique una técnica tan poderosa como una anáfora circular o, más bien, la cambie de lugar, porque repite "Ponte la flor" en el penúltimo verso. El último, a su vez, queda sometido al interlocutor, que, igual que en la segunda estrofa, no se limita a la simple observación: "Déjame llevarme como recuerdo/de tus grandes pies tu tacón jorobado, Flora". En conjunto, se produce una alteración del sentido enigmática y muy sutil, que no se percibe a primera vista, pero una lectura atenta, como debería ser la de un editor, es, sin duda, capaz de detectarla. Solo nos queda adivinar si los correctores de la "Isla de aurora purpúrea" no pudieron (los ejemplos de Nezval y Galczynski hacen suponer que Brodsky no era muy flexible con la corrección) o no quisieron cambiar la versión de "Vida de Flora" para no llamar demasiada atención y no correr el riesgo de que la quitaran de la antología, porque ya entendían que el ex "parásito social" que la creó era, de todo el colectivo de autores y traductores, el primer candidato a la eternidad.

\section{Referencias bibliográficas}

Klots, Yasha (2011). The Poetics and Politics of Joseph Brodsky as a Russian PoetTranslator. En: Baer, Brian James (ed.) 2006. Contexts, Subtexts and Pretexts: Literary Translation in Eastern Europe and Russia. Amsterdam-Philadelphia: John Benjamins Publishing. 187-204.

Алмой, Рала (2008). Весельй спутник. Воспоминания об Иосифе Бродском. СанктПетербург: Журнал Звезда.

Багно, Всеволод (2016). Аар особенный: художественный перевод в истории русккой культуры. Москва: Новое митературное обозрение. 
Вашкова, Аорета (2007). Silvestrovska noc - единственный перевод И. Бродского с чешского языка. Asequible en: https://www.radio.cz/ru/rubrika/bogema/bogema2007-07-14, fecha de consulta: 31-10-2019.

Вигдорова, Фрида (1988). Судилище. Огонек, 49. 26-31.

Гордин, Яков (2016). Пушкин. Бродский. Империя и судьба. Т. 2. Москва: Время.

Гумилев, Николай-Чуковский, Корней (1919). Принципь художественного перевода. Петербург: Всемирная митература.

Кулıэ, Виктор (1996). Перенос греческого портика на широту тундры. Аитературное обозрение, 3. 8-10.

Кулиэ, Виктор (1992). Там, где они кончили, ты начинаешь. Примечания En: Бродский, Иосиф. 1992. Бог сохраняет все. Москва: МИФ. 5-6. 282-297.

Сергеев, Анарей (2013). Omnibus. Москва: Новое китературное обозрение.

Фейхоо, Самуэль, сост. (1968) Остров зари багряной. Москва: Художественная митература.

ЭАельман, Ольга (2007). Процесс Иосифа Бродского. Новый мир, 1. 152-167. 